\title{
Agricultural Net Carbon Effect and Agricultural Carbon Sink Compensation Mechanism in Hotan Prefecture, China
}

\author{
Chuanhe Xiong ${ }^{1,2}$, Degang Yang ${ }^{1 *}$, Jinwei Huo ${ }^{1}$, Guiling Wang ${ }^{1,2}$ \\ 'Xinjiang Institute of Ecology and Geography, Chinese Academy of Sciences, \\ Urumqi 830011, China \\ ${ }^{2}$ University of Chinese Academy of Sciences, Beijing 100049, China
}

Received: 17 June 2016

Accepted: 28 September 2016

\begin{abstract}
Agriculture is one of the main sources of anthropogenic greenhouse gases on the earth, but it also serves as a carbon sink, which has great potential for greenhouse gas absorption. Based on the scientific calculation system of carbon emissions and carbon sinks in agriculture, we calculated the carbon emissions and carbon sinks of agriculture using data from Hotan Prefecture for the period 1999-2014. The results showed that the net carbon sink (total carbon sinks and total carbon emissions) showed a stable increase trend in Hotan during 1999-2014. The carbon sinks level of agriculture in Hotan prefecture is more than three times of that in China and more than two times that in Xinjiang. Thus, the agricultural carbon sinks function of Hotan is obvious. To realize sustainable agricultural development and to transform agricultural carbon sinks into the power to promote regional economic development, we established the ecological compensation mechanism of agricultural carbon sinks from the aspects of the main body of compensation, compensation principle, compensation method, and compensation standard within the premise of the ecological function of carbon sinks in agriculture. We use the net carbon sinks amount multiplied by the unit price of carbon sinks to obtain the amount of agricultural carbon sinks compensation in this paper. Compensation methods include government compensation and market compensation. Government compensation mainly comprises financial, material, policy, and technical compensation. Market compensation mainly uses the carbon trading platform to compensate for the net carbon sinks of agriculture.
\end{abstract}

Keywords: agricultural carbon emissions, agricultural net carbon sinks, ecological compensation mechanism, Hotan Prefecture

*e-mail: dgyang@ms.xjb.ac.cn 


\section{Introduction}

In recent years, global climate change has brought significant adverse effects on human society and economic development, and gradually has become a global issue of universal concern in the international community. The IPCC fourth assessment report pointed out that the global average surface temperature increased 0.74 degrees and the sea level rose 0.17 meters over the past 100 years [1]. Secondary and tertiary industries are the leading sectors of carbon emissions, but the rapid development of agriculture is also an important inducement to accelerate the warming of the climate [2]. Greenhouse gas emissions from the agricultural ecosystem accounted for $13.5 \%$ of the world's total greenhouse gas emissions [3]. Approximately 17\% of China's carbon emissions are from agricultural emissions [4], which was higher than the global average.

Although agriculture is one of the main sources of anthropogenic greenhouse gases on earth, it also has a strong carbon sink function, which has great potential for greenhouse gas absorption. Crops absorb much $\mathrm{CO}_{2}$ through photosynthesis, and the carbon content can reach 43-58\% of total biomass [5]. A 2009 United States Environmental Protection Agency (EPA) report showed that total 2007 greenhouse gas emissions in the U.S. was the carbon equivalent of $71.5 \times 10^{8}$ tons, in which agricultural greenhouse gas emissions were $4.13 \times 10^{8}$ tons of carbon equivalent, but the greenhouse gas emissions absorbed by the entire agricultural system was $10.63 \times 10^{8}$ tons of carbon equivalent, which not only completely offset agricultural greenhouse gas emissions but also reduced the net emissions of greenhouse gases to $60.88 \times 10^{8}$ tons of carbon equivalent [6]. Cole estimated that the world's carbon sequestration of farmland will be 20-30 Pg in the next 50-100 years [7]. Lal et al. showed that the total carbon sequestration potential of arable land was $0.75-1.0 \mathrm{Pg} / \mathrm{a}[8]$.

Global warming caused by greenhouse gas emissions has become a big challenge to the survival and development of human beings. There are two main ways to reduce the accumulation of greenhouse gases in the atmosphere: reducing greenhouse gas emissions and increasing the absorption of greenhouse gases - especially carbon dioxide - through carbon sinks. As a result, the structural characteristics and mechanisms of agricultural carbon emissions and carbon sinks have recently become popular topics for research and analysis. Jane M. F. Johnson et al. and Ray Massey et al. have estimated the United States' agricultural greenhouse gas emissions and carbon sinks [9-10]. The latter study results show that total agricultural carbon emission in 2008 was $4.28 \times 10^{8} \mathrm{t}$ carbon dioxide equivalent, in which the carbon emissions caused by the planting industry (including agricultural material input, rice fields, and soil carbon emissions), livestock intestinal fermentation and livestock manure were $2.25 \times 10^{8} \mathrm{t}$, $1.41 \times 10^{8} \mathrm{t}$, and $0.62 \times 10^{8} \mathrm{t}$ carbon dioxide equivalent, respectively. Woodlands were the most important carbon sink, absorbing approximately $7.92 \times 10^{8} \mathrm{t}$ carbon dioxide equivalent of greenhouse gases [10]. Embodied fossil fuel
$\mathrm{C}$ in the form of nitrogen fertilizer is one of the largest energy inputs to agriculture (over $60 \%$ in UK and USA) and hence should be a major target for GHG mitigation $[3,11]$. By 2040, forest soil carbon sink accounted for the proportion of forest vegetation carbon sink will increase by about $30 \%$ in Europe's 14 countries [12]. Tian Yun et al., Li Guozhi et al., and $\mathrm{Hu}$ Xiangdong et al. studied China's agricultural carbon emissions of land use, agricultural energy, and livestock breeding, respectively [13-15]. The carbon footprint of China's farmland was studied by Duan Huaping et al. [16], while Ernesto et al. discussed the soil net carbon sink and farming income and determined the optimal crop-planting patterns [17]. On the basis of calculating the net carbon sinks of agriculture, Michael Popp et al. discussed how to implement carbon compensation in agriculture [18]. There is also much research about changing agricultural land use and the carbon balance of the ecosystem [19-22]. The results of these studies have undoubtedly greatly enriched carbon emissions research, which has laid a solid foundation for this follow-up study. However, as the research deepens, limitations emerge. For example, much of the current research is about agricultural carbon emissions, but there is relatively less research about agricultural carbon sinks. Additionally, the results of the agricultural carbon emissions and carbon sinks research are mostly limited to cropland ecosystems and not extended to the field of animal husbandry. Finally, there are few studies involving compensation for agricultural carbon sinks.

Hotan Prefecture is located in the southernmost tip of Xinjiang Uygur Autonomous Region. It covers an area of approximately $248,100 \mathrm{~km}^{2}$, with mountains accounting for $33.3 \%$, deserts $63 \%$, and oases $3.7 \%$. The oases are divided into more than 300 subsections by desert and The Gobi. Its economy is dominated by agriculture [2, 23]. Hotan prefecture has many windbreaks. To make full use of local resources, expand the economic benefits of agriculture, and increase the income of the farmers, Hotan has developed its characteristic forestry and fruit industry for more than 15 years. The woodland area was $13.47 \times 10^{4}$

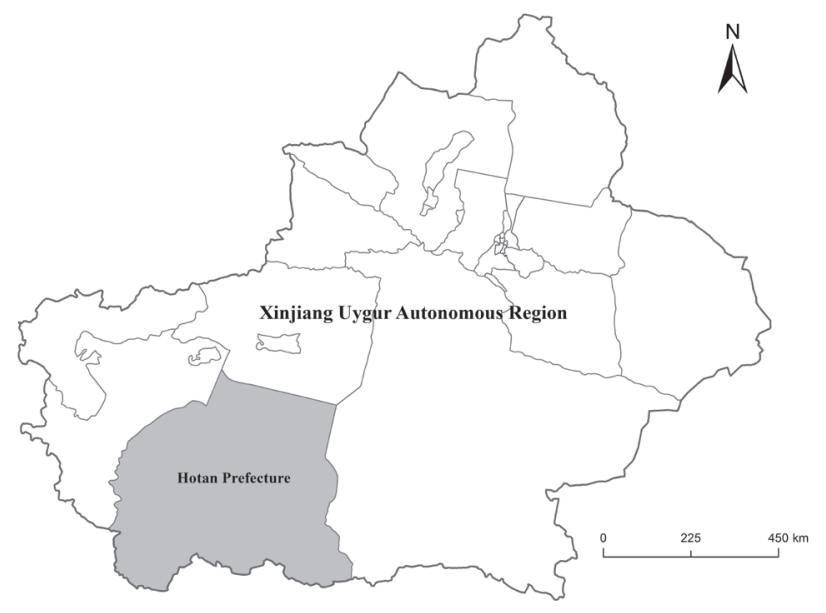

Fig. 1. Location of Hotan Prefecture. 
hectares in 1999 and was increased to $36.59 \times 10^{4}$ hectares in 2013 [2, 23]. Thus, the agricultural carbon sink function of Hotan is clear. Therefore, based on the scientific calculation system of carbon emissions and carbon sinks in agriculture (unlike Tian Y. et al., who calculated only the carbon emissions and carbon sinks of the farmland system [24]), we calculated the carbon emissions and carbon sinks of the agro ecological system in Hotan between 1999 and 2014. To encourage sustainable development and promote regional economic development, we studied how to set up the ecological compensation mechanism of agricultural carbon sinks using the following components: the main body of compensation, the compensation principle, the compensation method, and the compensation standard. Through this mechanism, the content of ecological compensation is enriched and the ecological benefits of agricultural carbon sinks are compensated. Meanwhile, we can also promote poverty alleviation and development, increase the income of farmers, promote rapid rural economic development, encourage sustainable agricultural development, and make due contribution to alleviating global climate change.

\section{Material and Methods}

\section{Calculation Method of Carbon Sinks in Agriculture}

In this paper, carbon sinks are mainly considered soil carbon sequestration of cultivated land, throughout the life cycle of crop growth and in carbon absorption in the characteristic forestry and fruit industry, because these are industries in which the farmers' participation and material costs are much higher. Without considering the carbon sink of woodland and grassland, this is mainly due to the following two reasons: on the one hand, human impact on woodland and grassland is relatively small, artificial participation intensity is not high, and input of energy and material cost are far less than the planting and characteristic forestry and fruit industries. On the other hand, for the carbon sequestration capacity of woodland and grassland, carbon sink calculation has not yet formed a unified standard, and there is a big difference between the result calculated by different methods.

\section{Calculation Method of Soil Carbon Sequestration of Cultivated Land}

The formula for calculating soil carbon sequestration of cultivated land is as follows:

$$
C S=S \times S O C D
$$

...where $C S$ is the total soil carbon sequestration of cultivated land, $S$ is the cultivated land area, and SOCD is the carbon density of cultivated land (which refers to the research of Lu Jingjing et al. [25]).

\section{Calculating Carbon Sinks in the Planting Industry}

In the case of carbon sinks from plant production, we consider carbon absorption throughout the life cycle of the main crops. The formula for calculating carbon sinks from the planting industry is:

$$
C P=\sum_{i=1}^{k} C_{i}=\sum_{i=1}^{k} c_{i} \bullet Y_{i} \bullet\left(1-r_{i}\right) / H I_{i}
$$

...where $C P$ is total carbon absorption in the planting industry, $C_{i}$ is the carbon absorption of crop $i, k$ is the number of crop species, $c_{i}$ is the carbon that crop $i$ needs to absorb for the production of per unit organic matter through photosynthesis, $Y_{i}$ is the economic yield of crop $i, r_{i}$ is the water content of the crop's economic products of crop $I$, and $H I_{i}$ is the economic coefficient of crop $i$. The economic coefficient, the water content of the crop's economic products, and the carbon uptake rate of the main crops in Hotan are from the research of Wang et al. and Han et al. [26-27].

\section{Calculation Method of Carbon Sinks in Characteristic Forestry and Fruit Industry}

Combining the results of past research [28-31] and expert suggestions, commercial forestry soil carbon sinks and understory vegetation carbon sinks are no longer calculated because the agricultural production pattern of Hotan alternates forest and agriculture crops. Therefore, the formula for calculating the carbon sinks in characteristic forestry and fruit industry are:

$$
\begin{gathered}
C F=\sum(S F \times C) \\
C=V \times \delta
\end{gathered}
$$

...where $C F$ is the total carbon absorption in characteristic forestry and fruit industry, $S F$ is the area of the commercial forestry, $C$ is the biomass carbon density, $V$ is biomass of commercial forestry per unit area, and $\delta$ is the conversion coefficient. In this paper, $V$ is $23.7 \mathrm{t} / \mathrm{hm}^{2}$ and $\delta$ is 0.48 [29, 31].

\section{Calculation Method of Agricultural Carbon Emissions}

According to past research [2, 23, 32-33], agricultural carbon emissions mainly come from agricultural land use, the $\mathrm{CH} 4$ gas emissions produced during the growth and development of rice, and carbon emissions from livestock farming. We establish the agricultural carbon emissions formula as:

$$
E=\sum E_{i}=\sum T_{i} \mu_{i}
$$


...where $E$ is total carbon emissions, $E_{i}$ is carbon emissions of carbon source $i, T_{i}$ is the amount of carbon source $I$, and $\mu_{i}$ is the carbon emission coefficient of carbon source $i$. To facilitate the analysis, we converted $\mathrm{CH}_{4}$ and $\mathrm{N}_{2} \mathrm{O}$ to standard carbon. All coefficients are from research by Xiong Chuanhe [2].

\section{Data Description}

Commercial forestry data are from the Bureau of forestry and other data in this study come from the Hotan Prefecture statistical yearbooks (2000-15).

\section{Results}

\section{Carbon Sinks in Agriculture}

Using Eqs 1-4, we obtained the agricultural carbon sinks in Hotan based on a data consolidation calculation (Table 1). The results showed that the agricultural carbon sinks were $6,271.03 \times 10^{3} \mathrm{t}$ in Hotan in 2014, while the soil carbon sequestration of cultivated land, the carbon absorption from plant production, and commercial forestry were $2,512.74 \times 10^{3} \mathrm{t}, 1,633.87 \times 10^{3} \mathrm{t}$, and $2,124.43 \times 10^{3} \mathrm{t}$, respectively.

The total agricultural carbon sinks increased rapidly to $1,823.20 \times 10^{3} \mathrm{t}$ - an increase of $40.99 \%$ during 1999 2014. The carbon absorption from plant production had fluctuating growth, which increased $550.17 \times 10^{3} \mathrm{t}$, an

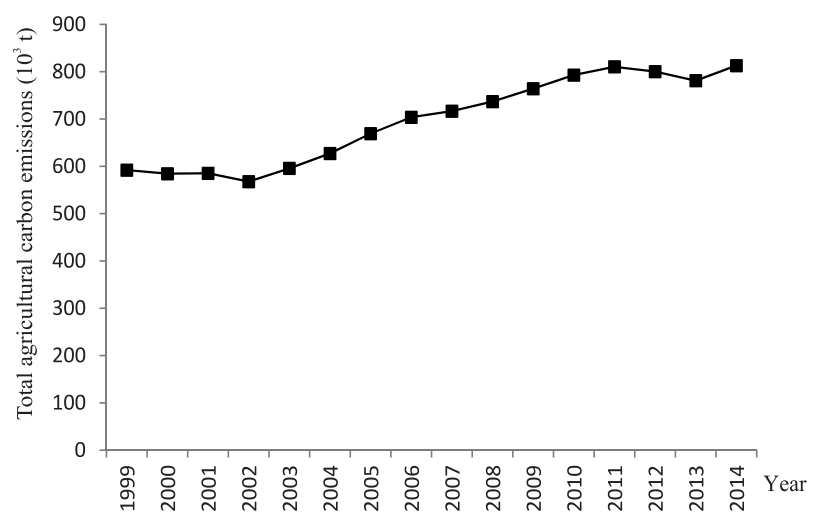

Fig. 2. Changes in total agricultural carbon emissions in Hotan Prefecture (1999-2014).

increase of $50.77 \%$ during $1999-2014$. The soil carbon sequestration of cultivated land remained unchanged at around $2,380 \times 10^{3} \mathrm{t}$ during the same period. The carbon absorption in the characteristic forestry and fruit industry increased rapidly, to $1,136.35 \times 10^{3} \mathrm{t}$ - increasing by $115.00 \%$ and accounting for $62.33 \%$ of the agricultural carbon sinks increment during 1999-2014.

\section{Carbon Emissions from}

Agricultural Production

Using Eq. 5, we calculated the agricultural carbon emissions from 1999 to 2014 in Hotan (Fig. 2).

Table 1. Carbon absorption of agricultural production in Hotan Prefecture from 1999 to 2014 (103 tons).

\begin{tabular}{|c|c|c|c|c|c|c|c|c|c|}
\hline Year & $\begin{array}{c}\text { Planting } \\
\text { industry }\end{array}$ & $\begin{array}{c}\text { Growth } \\
\text { rate } \%\end{array}$ & Soil & $\begin{array}{c}\text { Growth } \\
\text { rate } \%\end{array}$ & $\begin{array}{c}\text { Characteristic } \\
\text { forestry and fruit } \\
\text { industry }\end{array}$ & $\begin{array}{c}\text { Growth } \\
\text { rate } \%\end{array}$ & $\begin{array}{c}\text { The total } \\
\text { carbon sinks }\end{array}$ & $\begin{array}{c}\text { The total } \\
\text { carbon sinks } \\
\text { growth }\end{array}$ & $\begin{array}{c}\text { Growth rate } \\
\%\end{array}$ \\
\hline 1999 & $1,083.70$ & - & $2,376.06$ & - & 988.08 & - & $4,447.83$ & & - \\
\hline 2000 & $1,097.21$ & 1.25 & $2,350.90$ & -1.06 & $1,048.50$ & 6.11 & $4,496.61$ & 48.77 & 1.10 \\
\hline 2001 & $1,132.13$ & 3.18 & $2,353.75$ & 0.12 & $1,160.41$ & 10.67 & $4,646.29$ & 149.68 & 3.33 \\
\hline 2002 & $1,194.32$ & 5.49 & $2,317.71$ & -1.53 & $1,280.41$ & 10.34 & $4,792.44$ & 146.15 & 3.15 \\
\hline 2003 & $1,445.90$ & 21.06 & $2,308.90$ & -0.38 & $1,339.28$ & 4.60 & $5,094.09$ & 301.65 & 6.29 \\
\hline 2004 & $1,567.38$ & 8.40 & $2,325.74$ & 0.73 & $1,364.22$ & 1.86 & $5,257.34$ & 163.25 & 3.20 \\
\hline 2005 & $1,621.90$ & 3.48 & $2,340.57$ & 0.64 & $1,381.53$ & 1.27 & $5,343.99$ & 86.66 & 1.65 \\
\hline 2006 & $1,517.11$ & -6.46 & $2,340.42$ & -0.01 & $1,392.95$ & 0.83 & $5,250.48$ & -93.51 & -1.75 \\
\hline 2007 & $1,432.05$ & -5.61 & $2,378.78$ & 1.64 & $1,414.70$ & 1.56 & $5,225.54$ & -24.94 & -0.48 \\
\hline 2008 & $1,513.01$ & 5.65 & $2,388.67$ & 0.42 & $1,449.31$ & 2.45 & $5,350.99$ & 125.45 & 2.40 \\
\hline 2009 & $1,554.10$ & 2.72 & $2,390.40$ & 0.07 & $1,526.24$ & 5.31 & $5,470.75$ & 119.76 & 2.24 \\
\hline 2010 & $1,628.12$ & 4.76 & $2,374.15$ & -0.68 & $1,638.62$ & 7.36 & $5,640.90$ & 170.15 & 3.11 \\
\hline 2011 & $1,636.94$ & 0.54 & $2,363.06$ & -0.47 & $1,765.31$ & 7.73 & $5,765.31$ & 124.41 & 2.21 \\
\hline 2012 & $1,600.72$ & -2.21 & $2,375.69$ & 0.53 & $1,864.26$ & 5.61 & $5,840.67$ & 75.35 & 1.31 \\
\hline 2013 & $1,558.23$ & -2.65 & $2,387.05$ & 0.48 & $1,956.97$ & 4.97 & $5,902.25$ & 61.59 & 1.05 \\
\hline 2014 & $1,633.87$ & 4.85 & $2,512.74$ & 5.27 & $2,124.43$ & 8.56 & $6,271.03$ & 368.78 & 6.25 \\
\hline
\end{tabular}


Table 2. Agricultural production total net carbon sinks in Hotan Prefecture from 1999 to 2014 (10 $0^{3}$ tons).

\begin{tabular}{|c|c|c|c|c|c|}
\hline Year & $\begin{array}{c}\text { Total carbon } \\
\text { emissions }\end{array}$ & $\begin{array}{c}\text { Carbon sinks of } \\
\text { planting industry }\end{array}$ & $\begin{array}{c}\text { Total } \\
\text { carbon sinks }\end{array}$ & $\begin{array}{c}\text { Net carbon sinks } \\
\text { (total carbon sinks-total } \\
\text { carbon emissions) }\end{array}$ & $\begin{array}{c}\text { Carbon sinks level } \\
\text { (net carbon sinks / carbon } \\
\text { emissions) }\end{array}$ \\
\hline 1999 & 591.99 & $1,083.70$ & $4,447.83$ & $3,855.84$ & 6.51 \\
\hline 2000 & 584.38 & $1,097.21$ & $4,496.61$ & $3,912.23$ & 6.69 \\
\hline 2001 & 585.38 & $1,132.13$ & $4,646.29$ & $4,060.90$ & 6.94 \\
\hline 2002 & 567.64 & $1,194.32$ & $4,792.44$ & $4,224.80$ & 7.44 \\
\hline 2003 & 595.72 & $1,445.90$ & $5,094.09$ & $4,498.37$ & 7.55 \\
\hline 2004 & 627.20 & $1,567.38$ & $5,257.34$ & $4,630.14$ & 6.99 \\
\hline 2005 & 669.21 & $1,621.90$ & $5,343.99$ & $4,674.78$ & 6.46 \\
\hline 2006 & 703.79 & $1,517.11$ & $5,250.48$ & $4,546.69$ & 6.29 \\
\hline 2007 & 716.66 & $1,432.05$ & $5,225.54$ & $4,508.88$ & 6.26 \\
\hline 2008 & 736.83 & $1,513.01$ & $5,350.99$ & $4,614.16$ & 6.16 \\
\hline 2009 & 764.12 & $1,554.10$ & $5,470.75$ & $4,706.63$ & 6.11 \\
\hline 2010 & 792.85 & $1,628.12$ & $5,640.90$ & $4,848.05$ & 6.11 \\
\hline 2011 & 810.41 & $1,636.94$ & $5,765.31$ & $4,954.90$ & 6.30 \\
\hline 2012 & 800.25 & $1,600.72$ & $5,840.67$ & $5,040.41$ & 6.56 \\
\hline 2013 & 781.05 & $1,558.23$ & $5,902.25$ & $5,121.21$ & $5,458.11$ \\
\hline 2014 & 812.92 & $1,633.87$ & $6,271.03$ & & \\
\hline
\end{tabular}

Total agricultural carbon emissions showed a rapid growth trend of $591.99 \times 10^{3}$ tons in 1999 and $812.92 \times 10^{3}$ tons in 2014 . Agricultural carbon emissions increased by $37.32 \%$, with an average annual growth rate of $2.14 \%$.

\section{Net Carbon Sinks of Agricultural Production}

We used Eqs. 1-5 to obtain the net carbon sinks of agricultural production from 1999 to 2014 in Hotan (Table 2). The results show that the net carbon sinks for agricultural production in Hotan in 2014 is $5,458.11 \times 10^{3} \mathrm{t}$. The carbon absorption of the planting industry is $1,633.87 \times 10^{3} \mathrm{t}$, which not only completely offset the agricultural carbon emissions but also increased the net carbon sinks of agricultural production to $5,458.11 \times 10^{3} \mathrm{t}$.

The net carbon sink showed a stable increase trend in Hotan during 1999-2014. The carbon sinks level of agriculture in Hotan is more than three times of that in the planting industry. Thus, the agricultural production carbon sink function of Hotan is clear. Hotan will further optimize its agricultural production structure. At the same time, it will vigorously develop low-carbon agriculture and move toward modern agriculture. Needless to say, the agricultural production potential of carbon sinks in the prefecture is huge.

\section{Agricultural Carbon Sink Compensation Mechanism}

It is necessary to establish a mechanism for compensating the services of agricultural carbon sinks. This compensation will promote regional economic development. In particular, compensation for carbon sinks could alleviate poverty and promote sustainable development of impoverished areas such as Hotan Prefecture. To establish the compensation mechanism of agricultural carbon sinks, it is necessary to determine who will compensate and who will be compensated (the compensation body), how much to compensate (the compensation standard), and how to compensate (the compensation method). The standard of compensation is the key to establishing this mechanism.

\section{Compensation Principle}

The compensation principle is the premise of the establishment of the ecological compensation mechanism of agricultural carbon sink function, which is also the guiding principle of the construction of compensation mechanism. The establishment of a compensation mechanism should conform to social justice, reflect the principle of the beneficiary pay, and ensure the sustainable development of agriculture. 
The principle of fairness is the most basic principle of the ecological compensation mechanism. People's environmental rights are equal, and the rights to development are also equal. The core of the fairness principle is the exchange; the system of ecological compensation requires that the groups that benefit more than they are paid must pay for the compensation and the groups that pay more than they benefit must receive compensation.

The principle of the beneficiaries pay is the basic principle of ecological compensation and the basis of the determination of the compensation body. The core idea is that the beneficiaries of the ecological benefits should pay the corresponding cost to the provider of the ecological service. The compensation of agricultural carbon sinks requires that the ecological beneficiaries pay compensation to agricultural practitioners (the providers of carbon sinks) through government compensation or market compensation (such as carbon trading).

The sustainable principle requires that the compensation be integrated ecologically and economically, and it should promote social harmony and sustainable development (which changes the traditional compensation method for ecological compensation) [34]. Specifically, to promote sustainable development, the compensation for carbon sinks needs to take into consideration the development between the groups and the region. The region that receives the ecological benefit can compensate the region that provides agricultural carbon sinks to encourage agricultural production and protection and to promote regional balanced and sustainable development.

\section{Compensation Subject and Object}

Agricultural carbon sink compensation belongs to a category of agricultural ecological compensation, and the main body includes people, groups, or regions that compensate or are compensated. The main body that is compensated should have a positive ecological impact. The main body that is compensated for agricultural carbon sinks should be agricultural practitioners, that is, the farmers.

In theory, the main body that compensates is the beneficiary of the ecological protection, but because all people are the beneficiaries of environmental protection behavior, the government, as the representative of the people, becomes the main body of compensation. The local government has the responsibility to do well in ecological protection and construction in this area, so it is also the main body of compensation. Public goods can be divided into national public goods and local public goods according to the range of benefit; the difference between them is whether they are restricted by geographical space. National public goods are provided by the central government, whereas local public goods are provided by local governments. Agricultural carbon sinks benefit all of society, and the ecological benefit is obviously national, so the compensation of agricultural carbon sinks should be provided by the central government.

In addition, the other main body that compensates is the business sector. Business activities generally involve the use of natural resources or have a certain impact on the natural environment. In an effort to profit, enterprises often emit pollutants exceeding emissions targets. In the spirit of "who destroys, who renews," "who created pollution is responsible to suppress," and "who benefits, who pays," these business enterprises should be the main body of compensation.

\section{Compensation Standard}

Agricultural carbon sink compensation needs its own unique compensation standard. Agricultural products have economic value, and farmers earn the economic value by selling their agricultural products to recoup the cost of production and management. Agricultural carbon sinks are by-products of agriculture. Thus, the amount of ecological compensation should be determined according to the net carbon sinks produced by agriculture. Thus, we determine the compensation value in Hotan based on multiplying the price per unit of carbon sinks by the net carbon sinks in the prefecture.

According to data from China's carbon emissions trading network (www.tanpaifang.com), the trading volume of China's seven carbon trading pilot points in the secondary market was $1,360.5 \times 10^{4} \mathrm{t}$ carbon dioxide equivalent, and the total turnover was $4.92 \times 10^{8}$ yuan in 2014. Therefore, we can calculate the average price, which was 36.19 yuan per ton of carbon dioxide equivalent in China's carbon trading market in 2014. Through the above analysis, we can calculate the suitable compensation for agricultural carbon sinks in Hotan in 2014 (Table 3).

\section{Compensation Method}

The method of compensation for the agricultural carbon sink function is divided between the government and the market.

Table 3. Carbon sink benefits to agricultural production in Hotan Prefecture in 2014.

\begin{tabular}{|c|c|c|c|c|}
\hline Net carbon sinks & Net carbon sinks & \multirow{2}{*}{$\begin{array}{c}\text { Price per unit of } \\
\text { carbon sinks } \\
(\text { yuan } / \text { ton })\end{array}$} & $\begin{array}{c}\text { Total carbon } \\
\text { sinks benefits } \\
\left(10^{6} \text { yuan }\right)\end{array}$ & $\begin{array}{c}\text { Carbon sink benefits } \\
\left(\text { yuan } / \mathrm{hm}^{2}\right)\end{array}$ \\
\hline \begin{tabular}{c|c|c|c|}
$\left(10^{3}\right.$ tons carbon \\
equivalent $)$
\end{tabular} & $20,013.08$ & 36.19 & 724.27 & $3,920.08$ \\
\hline $5,458.11$ & equivalent $)$ & $\left(10^{3}\right.$ tons carbon dioxide & \\
\hline
\end{tabular}




\section{Government Compensation}

Government compensation is a type of compulsory, command and control mode of compensation whose main body is the government, which is an indirect ecological compensation. The government compensates through financial compensation, material compensation, policy compensation, and technical compensation, as detailed below.

The government's financial compensation involves a direct public payment, and the government directly pays compensation to the rural landowners and other ecological service providers. Essentially, the government purchases the ecosystem services and provides them to the user free of charge. The government's financial compensation comes in the form of tax returns, special funds, financial aid, financial subsidies, and incentives [34].

The government's material compensation includes providing actual goods to farmers. Its purpose is to help farmers reduce carbon emissions, increase carbon sinks, and protect and promote agricultural carbon sinks. Specifically, this material compensation might provide farmers with the relevant machinery and equipment for energy saving and emission reduction, such as new watersaving irrigation facilities. To reduce the production costs and increase the enthusiasm of farmers, the government should give some material support.

The government's policy compensation is mainly policy tilt, which includes the implementation of local tax relief, preferential arrangements for the region's infrastructure, and the realization of the ecological priority assessment policy. Policy compensation has the advantages of having low operational costs, little financial pressure, etc.

Technical compensation refers to the technical support provided by the central and local governments for the comprehensive prevention and control of ecological environments [35]. The government can provide farmers with free low-carbon training and increase the farmers' low carbon awareness and farmland management levels so that farmers can reduce the use of pesticides and chemical fertilizers and increase the use of manure in the agricultural production process. To further increase agricultural carbon sequestration, the government can also promote free soil formulation technology, soil carbon sequestration technology, etc.

\section{Market Compensation}

Market compensation refers to the activity of the spontaneous participation in the improvement of the ecological environment, in which market trading entities participate in the environmental market property rights transactions by economic means within the scope of various ecological and environmental standards, laws, regulations, and policies [36]. According to China's carbon emissions trading network, China will launch a national carbon emissions market in 2017. Enterprises, social groups, and other market players that are in accordance with the transaction rules will be able to carry out carbon trading.

At present, China's carbon trading pilot is mainly for forest carbon sinks. Hotan has formed the production structure of the characteristic forestry and fruit, animal husbandry, and planting industries. Meanwhile, the agricultural production pattern of Hotan alternates between forest and agricultural crops. The rate of alternation of forest and agricultural crops was approximately $83.74 \%$, and the net area of grain was very small in 2014. Its agricultural carbon sinks mainly come from forestry in particular the characteristic forestry and fruit industry. Therefore, we believe that the net agricultural carbon sinks of Hotan can be used as forest carbon sinks and to implement carbon trading. To facilitate carbon trading, we propose the establishment of a carbon-trading platform that includes forest carbon sinks, pasture carbon sinks, and planting carbon sinks trading.

\section{Discussion}

The net carbon sink showed a stable increase trend in Hotan during 1999-2014. The carbon sinks level of agriculture in Hotan is more than three times that in China and more than two times that in Xinjiang (Table 2) [24]. Thus, the agricultural production carbon sink function of Hotan is clear: high carbon-sink agriculture.

In the course of agricultural emissions reduction, the three major mechanisms of incentive, tax, and compensation should be combined together to influence the agricultural production decision $[5,18,23,37,38]$. We establish the ecological compensation mechanism of agricultural carbon sinks based on the following aspects: the main body of compensation, the compensation principle, the compensation method, and the compensation standard, which is based on the ecological function of carbon sinks in agriculture. We have discussed the compensation standard of agricultural carbon sinks. We use the net carbon sinks value multiplied by the unit price of carbon sinks to obtain the compensation value for agricultural carbon sinks in this paper. The compensation method includes government compensation and market compensation. The method of compensation includes financial compensation, material compensation, policy compensation, and technical compensation. Market compensation mainly uses a carbon trading platform to compensate for the net carbon sinks of agricultural production. Through this mechanism, the ecological benefits of agricultural carbon sinks are compensated; meanwhile, Hotan will explore the mode of circular eco low-carbon agriculture. The shift to low $\mathrm{C}$ agriculture is a win-win-win change with short-term economic, social, and environmental benefits - and not just regarding its contribution to the mitigation of uncertain temporal and spatial climate change impacts.

Of course, due to the limitations of available data, more research is needed. Although we strove to build a perfect index system of agricultural carbon sinks, it still needs further refinement. 


\section{Conclusions}

Based on the scientific calculation system of carbon emissions and carbon sinks in agricultural, we measured the carbon emissions and carbon sinks of agricultural production in Hotan between 1999 and 2014. The results showed that the net carbon sink showed a stable increase trend in Hotan during 1999-2014. The carbon sinks level of agriculture in Hotan is more than three times that of China and more than two times that of Xinjiang. Thus, the value of the agricultural carbon sink function of Hotan is clear. The prefecture is comprised of the characteristic forestry and fruit industry, animal husbandry, and the planting industry and will further optimize its production. At the same time, Hotan will vigorously develop lowcarbon agriculture and move toward modern agriculture. Needless to say, the production potential of carbon sinks in Hotan is huge.

We established the ecological compensation mechanism of agricultural carbon sinks based on the following aspects: the main body of compensation, the compensation principle, the compensation method, and the compensation standard based on the ecological function of carbon sinks in agriculture. We are sure that the ecological benefits of agricultural carbon sinks will be compensated through the ecological compensation mechanism of agricultural carbon sinks in Hotan to promote poverty alleviation and development, increase the income of farmers, promote rapid rural economic development, encourage sustainable agricultural development, and contribute to alleviating global climate change.

\section{Acknowledgments}

This work was supported by the Study on Oasis Population Evolution and Transfer Way: A Case in Moyu County (XBBS-2014-11).

\section{References}

1. IPCC. Climate change 2007: Mitigation of climate change. Contribution of working group III to the fourth assessment report of the intergovernmental panel on climate change Cambridge. Cambridge University Press, London, 2007.

2. XIONG C.H., YANG D.G., HUO J.W. Spatial-temporal characteristics and LMDI-based impact factor decomposition of agricultural carbon emissions in Hotan Prefecture, China. Sustainability. 8 (3), 262:1-14, 2016.

3. NORSE D. Low carbon agriculture: objectives and policy pathways. Environment Development. 59, 25, 2012.

4. TIAN Y., ZHANG J.B., LI B. Agricultural carbon emissions in China: calculation, spatial- temporal comparison and decoupling effects. Resources Science. 34 (11), 2097, 2012.

5. XIA Q.L. Based on the carbon sink of agricultural development mode transition study. Ecological economy. 10, 106, 2010.

6. USEPA. Inventory of U.S. greenhouse gas emissions and sinks: 1990-2007. EPA 430-R-09-004. USEPA, Washington, DC, 2009.
7. COLE C.V. Agricultural Options for Mitigation of Greenhouse Gas Emission.WATSON R.T., ZNYOWERA M.C., MOSS R.H. Climate Change 1995-Impacts Adaptions and Mitigation of Climate Change Intergovernmental Panel on Climate Change. Cambridge: Cambridge University Press, $1,1996$.

8. LAL R., KIMBLE J.M., FOLLETT R.F., COLE C. . The Potential of US Cropland to Sequester Carbon and Mitigate the Greenhouse Effect. ChelseaMI: Sleeping Bear Press. 128, 1998.

9. JOHNSON JANE M.F. Agricultural opportunities to mitigate greenhouse gas emissions. Environmental Pollution. 150, 107, 2007.

10. RAY MASSEY, ANN ULMER. Agriculture and greenhouse gas emissions [EB /OL].http://extension.missouri.edu/p/ G310, 2010-08-16/2012-07-28.

11. BRENTRUP F., PALLIERE C. GHG emissions and energy efficiency in European nitrogen fertiliser production and use. In: Proceedings of International Fertiliser Society Conference, Cambridge, 11 December 2008. International Fertiliser Society, York, UK, 2008.

12. JARI L., DANIEL P., TIMO K. Increasing carbon stocks in the forest soils of western Europe. Forest Ecology and Management, 169 (1), 159, 2002.

13. TIAN Y., LI B., ZHANG J.B. Research on stage characteristics and factor decomposition of agricultural land carbon emission in China. Journal of China University of Geosciences: Social Sciences Edition. 11 (1), 59, 2011.

14. LI G.Z., LI Z.Z. Carbon emissions decomposition analysis on agricultural energy consumption - Based LMDI model. Journal of Agro technical Economics. 10, 66, 2010.

15. HU X.D., WANG J.M. Estimation of livestock greenhouse gases discharge in China. Transactions of the CSAE. 26 (10), 247, 2010.

16. DUAN H.P., ZHANG Y., ZHAO J.B., BIAN X.M. Carbon footprint analysis of farmland ecosystem in China. Journal of Soil and Water Conservation. 25 (1), 203, 2011.

17. ERNETO G.E., RODRIGUEZ L.C., WALEN V.K. Carbon sequestra-tion and farm income in West Africa: Identifying best management practices for smallholder agricultural systems in northern Ghana. Ecological Economics. 67 (3), 492, 2008.

18. POPP M., NALLEY L., FORTIN C., SMITH A., BRYE K. Estimating net carbon emissions and agricultural response to potential carbon offset policies. Agronomy Journal. 103 (4), 1132, 2011

19. FARGIONE J., HILL J., TILMAN D., POLASKY S., Peter HAWTHORNE P. Land clearing and the biofuel carbon debt. Science. 319 (10), 1235, 2008.

20. CARMELA B.M., AREVALO JAGTAR S. BHATTI. Land use change effects on ecosystem carbon balance: From agricultural to hybrid poplar plantation. Agriculture, Ecosystems and Environment. 141, 342, 2011.

21. LAL R. Soil erosion and the global carbon budget. Environment International. 29 (4), 437, 2003.

22. KINDLER R., SIEMENS J., KAISER K., WALMSLEY D.C. Dissolved carbon leaching from soil is a crucial component of the net ecosystem carbon balance. Global Change Biology. 17 (2), 1167, 2011.

23. XIONG C.H., YANG D.G., HUO J.W., ZHAO Y.N. The relationship between agricultural carbon emissions and agricultural economic growth and policy recommendations of a low-carbon agriculture economy in Hotan Prefecture, China. Polish Journal of Environmental Studies. 25 (5), 2187, 2016 . 
24. TIAN Y., ZHANG J.B. Regional differentiation research on net carbon effect of agricultural production in China. Journal of Nature Resource, 28 (8), 1298, 2013.

25. LU J.J., ZHOU Z.B., YAN B., DING X.Y., JIA H.T., WANG X.J. The analysis of cropland soil organic carbon sequestration rate and impacting factors in the process of oasisization of the irrigating area in Northern Tarim Basin. Arid Zone Research. 2016. (Accepted)

26. WANG X.L. Carbon Dioxide, Climate Change, and Agriculture. China Meteorological Press, Beijing, 1996.

27. HAN Z.Y., MENG Y.L., XU Ji., ZHOU Z G. Temporal and spatial difference in carbon footprint of regional farmland ecosystem - taking Jiangsu Province as a case. Journal of Agro-Environment Science. 31 (5), 1034, 2012.

28. FANG J.Y., GUO Z.D., PIAO S.L., CHEN A. P. Estimation of terrestrial vegetation carbon sinks in China from 1981 to 2000. Science in China (Series D: Earth Sciences). 37 (6), 804, 2007.

29. ZHANG M.Z., WANG G.X. The forest biomass dynamics of Zhejiang Province. Acta Ecologica Sinica. 28 (11), 5665, 2008 [In Chinese].

30. ZHANG D.D., ZHANG S.M., HUANG W. Estimation of carbon sources and sinks of the agricultural system in Zhejiang Province. Chinese Journal of Agricultural Resources and Regional Planning. 33 (5), 12, 2012.

31. LIU K., JIANG S.H., ZHU W.Y. Estimation of carbon sequestration value and analysis of space effect of forests in Guangdong Province. Chinese Journal of Agricultural Resources and Regional Planning. 36 (3), 120, 2015.

32. SONG D.Y., LU Z.B. The Factor Decomposition and Periodic Fluctuations of Carbon Emission in China. China Population, Resources and Environment. 19 (3), 18, 2009.

33. TIAN Y., ZHANG J.B., HE Y.Y. Research on SpatialTemporal Characteristics and Driving Factor of Agricultural Carbon Emissions in China. Journal of Integrative Agriculture. 13 (6), 1393, 2014.

34. ZHANG F., CAO J. Institutional Dilemma and Constructing Harmonious Mechanism of Interests on Agricultural Ecological Compensation Mechanism. Research of Agricultural Modernization. 31 (5), 538, 2010.

35. WANG O., SONG H.Y. On the Compensation Mechanism after Reverting Farmland to Forests or Grasslands: A Discussion. Problem of Agricultural Economy. (6), 22, 79, 2005.

36. ZHU G.Q., HAN H. Compensation Mechanism of Forest Ecological Benefit Based on Regional Carbon Trading. Journal of Northeast Forestry University. 38 (10), 109, 2010.

37. KNOKE T., STEINBEIS O., BOSCH M., ROMAN-CUESTA R.M., BURKHARDT T. Cost-effective compensation to avoid carbon emissions from forest loss: An approach to consider price-quantity effects and risk-aversion. Ecological Economics. 70 (6), 1139, 2011.

38. KRAGT M.E., GIBSON F.L., MASEYK F., WILSON K.A. Public willingness to pay for carbon farming and its cobenefits. Ecological Economics, 126, 125, 2016. 
